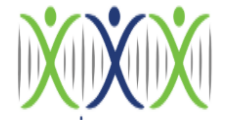

iRASD

\section{Pakistan Journal of Humanities and Social Sciences}

Volume 10, Number 1, 2022, Pages 20-28

Journal Homepage:

https://journals. internationalrasd.org/index.php/pjhss
PAKISTAN JOURNAL OF

\title{
Cyber-Psychopathy Trait as Predictor of Cybersex Addiction among University Students
}

\author{
Ahmad Bilal(D1, Arif Nadeem (D2, Muhammad Saleem (D)3 \\ ${ }^{1}$ Assistant Professor, Department of Applied Psychology, The Islamia University of Bahawalpur, Pakistan. \\ Email: ahmadbilal4@gmail.com \\ 2 Lecturer, Department of Applied Psychology, Government College University Faisalabad, Pakistan. \\ Email: arif.nadeem.79@gmail.com \\ ${ }^{3}$ Associate Professor, Department of Applied Psychology, The Islamia University of Bahawalpur, Pakistan. \\ Email: chsaleem_1@hotmail.com
}

\section{ARTICLE INFO}

\begin{tabular}{lr}
\hline Article History: & \\
Received: & December 12, 2021 \\
Revised: & January 12, 2022 \\
Accepted: & January 18, 2022 \\
Available Online: & January 18, 2022 \\
\hline Keywords: & \\
Addiction & \\
Cybersex & \\
Dark Triad & \\
Personality & \\
Psychopathy & \\
University Students \\
\hline
\end{tabular}

\section{ABSTRACT}

The previous studies have established a link between dark triad personality traits and cybersex addiction. However, there is a scarcity of studies on the link between psychopathy and cybersex addiction. Therefore, the present study was conducted to find an association and to predict cybersex addiction from psychopathy. 160 undergraduate students from the Baghdad campus of Islamia University of Bahawalpur were recruited randomly to participate in the study. All the participating students signed the informed consent form before taking part in the study. The locally standardized versions of The Internet Addiction Test - Sex (IAT-Sex) and Cyber-Psychopathy Scale (CPS) were used to collect the data. The data was analyzed through the Statistical Package for Social Sciences (SPSS, v 25) and expressed in the form of correlation, regression analysis, and $t$ test. The study found a significant positive correlation between psychopathy and cybersex addiction. The psychopathy significantly predicted cybersex addiction. Moreover, the male students showed more psychopathy and cybersex addiction to female students. The students of 21-22 years were found to show more psychopathy and cybersex addiction as compared to students of other age groups. The study proposed that future studies be conducted with broader sample from other universities and by including other demographic variables to make the results generalizable to a larger population.

(c) 2022 The Authors, Published by iRASD. This is an Open Access Article under the Creative Common Attribution Non-Commercial 4.0

Corresponding Author's Email: ahmadbilal4@gmail.com

\section{Introduction}

Generally, cybersex and cybersex addiction have been studied previously under the broader term of problematic internet use (PIU). The PIU has been found to be associated with certain personality traits by a number of earlier studies (Brand et al., 2016). On the other hand, a handful of studies established a link between dark triad (collection of negative personality traits of Machiavellianism, psychopathy, and narcissism) and PIU (Lu et al., 2017). Psychopathy which is one of the personality trait of dark triad has been found to be associated with sensational behaviors, callousness, and antisocial activities online. There has been a dearth of studies on the relationship of psychopathy with PIU or cybersex addiction (Kircaburun \& Griffiths, 2018).

Psychopathy can be characterized as a combination of high levels of impulsivity, recklessness, and low levels of empathy (Jonason, Zeigler-Hill, \& Okan, 2017). The individuals who possess the trait of psychopathy also display signs of emotional dysregulation and lower positive mood (Egan, Chan, \& Shorter, 2014). The psychopaths use PIU as a coping strategy (Kuss, D Griffiths, Karila, \& Billieux, 2014) and to obtain higher sensations (Lin \& Tsai, 2002). 
Cybersex refers to sexual activities performed through the use of internet or online. It encompasses behaviors such as viewing, uploading, or downloading pornographic content, reading erotic stories, searching sex partners online, exchanging sexual communication, sending and receiving sexual content through internet, masturbating while engaged in cybersex activities (Hald \& Mulya, 2013). Cybersex addiction is a variation of behavioral addiction which includes behaviors such as continuous engagement in cybersex activities, preoccupation, tolerance, withdrawal, loss of control, and mood regulation with the help of cybersex activities (Beutel et al., 2017). Usually, the cybersex addicts suffer from poor impulse control and have other comorbid addictions such as sex addiction, alcoholism or gambling, although sex addiction is different from cybersex addiction (Weinstein, Zolek, Babkin, Cohen, \& Lejoyeux, 2015). Cybersex addiction can be divided further into sub category of cyber relationship addiction which is searching for and developing online relationships for cybersex activities (Young, 1999, 2008).

Cybersex offers a variety of novel opportunities to explore and express one's sexuality, thereby deriving pleasure, thus it becomes difficult to quit cybersex activities despite negative or harmful consequences (Laier, Pekal, \& Brand, 2014; Young, 2008). Cybersex should not be confused with only pornography consumption, rather it encompasses a variety of sexual behaviors performed online (Snagowski \& Brand, 2015), though pornography consumption is most relevant for men (Short, Black, Smith, Wetterneck, \& Wells, 2012). Further, cybersex is different from hypersexuality (Kafka, 2010) and sex addiction (Reay, Attwood, \& Gooder, 2013).

Currently, there is no clear diagnostic category of cybersex addiction in both DSM and ICD so the criteria of internet addiction were modified to cover the cybersex behaviors including doing sexual things online, spending money online for sexual activities and to experience distress when unable to go online for sexual purposes (Edwards, 2009). These criteria are based on DSM's criteria of Internet Gaming Disorder (American Psychiatric Association, 2013).

The cybersex addiction has no clearly identified prevalence rates (Dhuffar \& Griffiths, 2015). Some studies conducted with English men report prevalence rates as $1 \%$ (Cooper, Delmonico, \& Burg, 2000) to 8.6\% (Cooper, Griffin-Shelley, Delmonico, \& Mathy, 2001). There are no statistics available from Pakistan on the use of pornography or cybersex (Ehsan, Ahmed, Asim, Devi, \& Ahmad, 2019).

\section{Review of Literature}

A number of earlier studies reported a direct link between psychopathy trait and problematic internet use through the mediating effect of online activities such as cybersex addiction (Buckels, Trapnell, \& Paulhus, 2014; Marcus, Zeigler-Hill, Mercer, \& Norris, 2014). More recently, a study with 772 Turkish university students with age $(M=20.72, S D=2.30)$ reported a direct link between psychopathy trait and PIU (Kircaburun \& Griffiths, 2018).

Recent studies pointed a relationship between pornography use and cybersex addiction. Both were used as a means to derive sexual pleasure (Laier, Pawlikowski, Pekal, Schulte, \& Brand, 2013). The relationship between pornography use and cybersex can be explained by applying the model given by Brand which explains relationship between internet addiction and cybersex addiction (Brand, Young, \& Laier, 2014). The pornography and cybersex are associated with each other and often predict each other (Weinstein et al., 2015).

Men have been found to engage in cybersex behavior four times more as compared to women $(21.5 \%$ vs $4.7 \%$ ) as found out by a German survey (Beutel et al., 2011; Beutel et al., 2017). One reason of gender differences in cybersex behavior is personality differences between genders. Men prefer the visual aspect of sexuality focusing more on video clips and images compared to women who focus more on chat or mutual communication exchange (Griffiths, 2001). Men enjoy the cybersex activities mostly when they are solitary while women considered solitary activity as a kind of cheating or something alien to their relationship (Bridges \& Morokoff, 2011; Nawaz, Afzal, \& Shehzadi, 2013). Women tend to make use of online sexual activities as part of lovemaking process or due to requests by their partners. This is so as women tend to prefer partnered fantasies and look for intimacy whereas men prefer erotic visual stimuli as provided by pornography (Weinstein et al., 2015). 
On the other hand, cybersex addiction serves different functions for both genders. Men use cybersex activities to regulate their mood (Paul \& Shim, 2008). Men report online sexual activities to be arousing for them (Boies, 2002) while majority of women report online sexual behaviors disgusting and disturbing (Nosko, Wood, \& Desmarais, 2007). The extent of engaging in online cybersex activities is determined by both personality traits and quality of offline sexual behaviors (Atiq-ur-Rehman, Ditta, Nawaz, \& Bashir, 2020; Brand, Young, Laier, Wölfling, \& Potenza, 2016; Kircaburun \& Griffiths, 2018).

Cybersex addiction poses serious emotional, psychological and relational consequences. Men get addicted to solitary sexual pleasure and do not feel the need to form intimate relationships, thereby affecting the quality of marital or intimate relationships (Weinstein et al., 2015). Such behaviors result in lowering the self-esteem of female partners as well as they consider themselves less attractive and failure in making their partners sexually satisfied. This ruin the quality of whole relationship.

Age has also been found to exert a significant influence in the prevalence of both psychopathy and cybersex addiction. A study with American college students of emerging age found that around $10.3 \%$ showed features of cybersex addiction (Giordano \& Cashwell, 2017; Javed, Nawaz, \& Qurat-UI-Ain, 2015). The prevalence of cybersex addiction had been found high as majority of emerging adults spend a lot of time on online activities including PIU (Anderson, Steen, \& Stavropoulos, 2017).

\section{Rationale \& Hypotheses}

Pakistan has a conservative culture where expression of sexuality is considered taboo and is prohibited (Ehsan et al., 2019). In Pakistan, sexuality is expressed within the boundaries of married heterosexual relationships. Pakistan resembles other Eastern cultures in this regard (Hald \& Mulya, 2013). Due to profound psychological, emotional, and legal repercussions of cybersex, Pakistan Telecommunication Authority banned around 800,000 porn websites in Pakistan in 2019 (New Indian Express, 2019). Despite Pakistan being the top country in banning the cybersex content (Tribune, 2020), yet the ratio of Pakistanis engaging in cybersex is still high. According to a study conducted with 16-24 years adolescents from urban areas of Pakistan, around $67.5 \%$ reported watching pornography (Ehsan et al., 2019). Around $52.6 \%$ of male adolescents and $47.4 \%$ female adolescents reported watching pornographic material at least once in a month. Previous studies reported an established link between watching pornographic material and developing cybersex addiction. Similarly, personality traits were conceptualized to predict cybersex addiction. Therefore, the present study was designed with an aim to find an association between psychopathy and cybersex addiction in undergraduate university students. Moreover, the study aimed to predict cybersex addiction from psychopathy. Further, it was assumed that male students had more psychopathy and more cybersex addiction as compared to female students. It was also assumed that lower age had a significant association with both psychopathy and cybersex addiction.

\section{Methods}

\subsection{Research Design}

The present research used the cross sectional and survey research designs.

\subsection{Participants \& Sampling}

160 undergraduate students of both gender $(M=80, F=80)$ were sampled randomly from the Baghdad campus of Islamia University of Bahawalpur. The sample size was calculated by using an online sample size calculator at surveymonkey.com. The calculated sample size was 380 with $95 \%$ confidence interval and 5\% margin of error. The response rate of participants was around $42 \%$. The low number of responses could be obtained due to the sensitivity of the research. The students of 18 to 25 years age $(M=21.27, S D=1.72)$ were included in the sample. All the participating students were required to sign the informed consent form before taking part in the study.

\subsection{Inclusion and Exclusion Criteria}

The undergraduate students studying in the Baghdad campus of Islamia University of Bahawalpur who were of 18 to 25 years age were included in the study. The students of other 
institutions, programs, and those below 18 years of age or above 25 years were excluded from the study.

\subsection{Instruments}

\subsubsection{Informed Consent \& Demographic Information Proforma (IC\&DIP)}

An informed consent form was developed to explain the research protocols to participating students. All the participating students were required to read and agree to the informed consent form before taking part in the study. A demographic information proforma was designed by the researchers that contained information about the age and gender of the participating students.

\subsubsection{Cyber Psychopathy Scale (CPS)}

The respondents are asked to rate 26 items that represent both dimensions of psychopathy together (primary and secondary) in the online context. These items are based on a 4-point Likert scale ranging from $1=$ "Disagree Strongly" to $4=$ "Agree Strongly", and the scoring on this scale is between 26 (minimum) and 104 (maximum). The internal consistency with Cronbach's is a=0.87 (Nevin, 2015).

\subsubsection{Internet Addiction Test-Sex (IAT-Sex)}

The Internet Addiction Test - Sex (Brand et al., 2011) is a modified version of the IAT in which the terms 'online' or 'Internet' in the original IAT were replaced by the terms 'online sexual activity' and 'Internet sex sites' respectively. This instrument aims to assess subjective complaints in everyday life due to online sexual activities and potential symptoms of cybersex addiction. This version consists of 20 items, and the Likert scale used ranges from 1 to 5 ('rarely' to 'always'), resulting in a score between 20 and 100 . Internal consistency (Cronbach's $a$ ) of this scale is .84 .

\subsection{Procedure}

The study was approved by the Research Committee of the department of Applied Psychology at The Islamia University of Bahawalpur, Pakistan. The data collection was allowed by the Chair of Department of Applied Psychology at Islamia University of Bahawalpur. The written informed consent was signed by all the participating male and female students before taking part in the study. The data was collected from the undergraduate students from the Baghdad campus of Islamia University of Bahawalpur by administering the IC\&DIP and the 2 scales.

The study maintained all ethical protocols of the research. The nature and rationale of the study including possible harms was explained to all participating students and informed consent was obtained from all the participating students before the start of the research. They were ensured about the confidentiality of their data. The data was analyzed by the Statistical Package for the Social Sciences (IBM, USA) version 25. The results were expressed in the form of socio-demographic characteristics of participating students, correlation between psychopathy and cybersex addiction, regression analysis to predict cybersex addiction from psychopathy and t test for finding gender differences in psychopathy and cybersex addiction.

\section{Results}

The table 1 outlines gender, education, and age as demographic variables.

Table 1: Frequency Distribution of all Demographic Characteristics $(N=160)$

\begin{tabular}{cccc}
\hline Respondents' Demographics & Demographic Characteristics & $\mathbf{F}$ & $\%$ \\
\hline \multirow{2}{*}{ Gender } & Male & 80 & 50.0 \\
& Female & 80 & 50.0 \\
\hline \multirow{2}{*}{ Education } & BS (Hons) & 70 & 43.75 \\
& MA/MSc & 90 & 56.25 \\
\hline \multirow{2}{*}{ Age (years) } & $\mathbf{1 8 - 2 0}$ & 60 & 37.50 \\
& $\mathbf{2 1 - 2 2}$ & 60 & 37.50 \\
& $\mathbf{2 3 - 2 5}$ & 40 & 25.0 \\
\hline
\end{tabular}

The Table 2 revealed the acceptable values of Cronbach's alpha for cyber psychopathy (.86) and cybersex addiction (.82) scales for reliability analysis. While, the values of skewness of all variables also showed the acceptable ranges. The Table 3 revealed that cyber 
psychopathy was significantly positively correlated with cybersex addiction among the university students.

Table 1: Descriptive Statistics and Psychometric Properties of Study Variables $(\mathbf{N}=160)$

\begin{tabular}{llllllll}
\hline \multirow{2}{*}{ Variables } & \multirow{2}{*}{ Items } & M & SD & $\boldsymbol{a}$ & \multicolumn{2}{c}{ Range } & Potential \\
Actual & Skew \\
\hline Age & - & 21.27 & 1.72 & - & - & $18-25$ & .51 \\
Cyber Psychopathy & 26 & 56.37 & 10.84 & .86 & $26-104$ & $36-100$ & .10 \\
Cyber Sex Addiction & 20 & 13.41 & 6.74 & .82 & $20-100$ & $20-80$ & .12 \\
\hline
\end{tabular}

Table 3: Correlation Analysis between Cyber Psychopathy and Cybersex addiction ( $\mathrm{N}=160)$

\begin{tabular}{cccc}
\hline & Variables & $\mathbf{1}$ & $\mathbf{2}$ \\
\hline & 1. Cyber Psychopathy & - & $0.71^{* *}$ \\
& 2. Cyber Sex Addiction & & - \\
\hline$* *<<.01$ & & &
\end{tabular}

Table 4: Impact of Cyber Psychopathy on Cybersex Addiction among university students $(\mathbf{N}=160)$

\begin{tabular}{ccc}
\hline & & Cybersex Addiction \\
\hline Predictors & Model 1 $\boldsymbol{\beta}$ & $\mathbf{9 5 \%} \boldsymbol{C I}$ \\
\hline Constant & $1.29^{* *}$ & {$[4.03,5.84]$} \\
Cyber Psychopathy & $.71^{* *}$ & {$[.6, .4]$} \\
$\mathbf{R}^{\mathbf{2}}$ & .62 & \\
$\mathbf{F}$ & $.86^{* *}$ & \\
\hline
\end{tabular}

${ }^{* *} p<.01 ; \beta=$ Unstandardized regression coefficient; CI = Confidence interval

The Table 4 revealed that cyber psychopathy is strong predictor $\left(\mathrm{R}^{2}=.624, p<.01\right)$ of cybersex addiction among university students.

Table 5: Independent Sample t-test for Gender Differences between Cyber Psychopathy and Cybersex Addiction $(\mathrm{N}=160)$

\begin{tabular}{|c|c|c|c|c|c|}
\hline \multirow{2}{*}{ Variable } & \multirow{2}{*}{$\begin{array}{c}\text { Male }(n=80) \\
\quad M(S D)\end{array}$} & \multirow{2}{*}{$\begin{array}{c}\text { Female }(\mathrm{n}=80) \\
M(S D)\end{array}$} & \multirow[b]{2}{*}{$\boldsymbol{t}$} & \multicolumn{2}{|c|}{$95 \% C I$} \\
\hline & & & & $\boldsymbol{L L}$ & $U L$ \\
\hline Cyber F & $58.44(13.19)$ & $53.37(11.26)$ & $-5.48 * *$ & -10.90 & -4.41 \\
\hline Cybersex Ac & $12.03(09.28)$ & $10.52(11.67)$ & $-3.29 *$ & -11.96 & 3.82 \\
\hline
\end{tabular}

The Table 5 shows that mean score of cyber psychopathy and cybersex addiction is higher among male university students.

Table 6: One Way ANOVA Used for Comparison among Age of Respondents for Study Variables $(\mathrm{N}=160)$

\begin{tabular}{llllllllll}
\hline Variable & $\mathbf{1 8 - 2 0}(\boldsymbol{n}=\mathbf{6 0})$ & $\mathbf{2 1 - 2 2}(\boldsymbol{n}=\mathbf{6 0})$ & $\mathbf{2 3 - 2 5}(\boldsymbol{n}=\mathbf{4 0})$ & & \multicolumn{1}{c}{$\boldsymbol{n p}^{\mathbf{2}}$} \\
\hline $\begin{array}{l}\text { Cyber } \\
\begin{array}{l}\text { Psychopathy } \\
\text { Cybersex }\end{array}\end{array}$ & 55.12 & 12.22 & 56.32 & 14.11 & 53.42 & 11.21 & 4.67 & .013 & .03 \\
Addiction & 13.57 & 4.12 & 14.22 & 5.31 & 11.78 & 3.95 & 7.19 & .000 & .04 \\
\hline
\end{tabular}

$n p^{2}=$ partial eta square

The Table 6 shows that age of respondents showed significant difference in the mean scores of cyber psychopathy and cybersex addiction. While, the mean of cyber psychopathy and cybersex addiction were higher among respondents with age range 21-22 years, however, the effect size was small for both cyber psychopathy and cybersex addiction.

\section{Discussion}

To the best of authors' knowledge, the current study was the first to predict and find an association between psychopathy and cybersex addiction in Pakistani undergraduate university 
students. Psychopathy, like other dark triad personality traits had been shown to be associated with cybersex addiction by a number of Western studies. The present study found a significant positive correlation between psychopathy and cybersex addiction. The emotional and mood dysregulation, impulsivity, callousness, deceitfulness, risky and sensational behaviors were the maintaining factors in relationship between psychopathy and cybersex addiction (Brand et al., 2016; Lu et al., 2017). It is still possible that cybersex addiction develops first and leads to psychopathy traits. In Pakistan, adolescents and young adults turn towards internet for seeking information related to sexuality related matters as there is no formal sex education in Pakistan and majority of households consider it taboo to talk about sexual matters, so internet becomes the only source of information (Ehsan et al., 2019). Such milieu prepares the stage for falling prey to pornographic watching and later becoming addict to it as pornographic consumption leads to loss of control to quit excessive internet use and results in other features of behavioral addiction (Kayiş et al., 2016).

The reliance on internet has several reasons rooted in the family culture. One of the foremost is the lack of communication skills in real world and disturbed parent child relationships (Liau, Khoo, \& Ang, 2008). Another reason is to making use of internet to ward off the impact of daily stressors in life (Lam, Peng, Mai, \& Jing, 2009). It has been found that parental regulations relating to the internet use should be swift and need to be administered in consultation with the adolescents. Previously, it was noted that strict parental control of the internet use resulted in three time increase in seeking sexual content online (Liau et al., 2008; Ybarra \& Mitchell, 2005). Recent studies with Pakistani university students found an association between psychopathic traits such as promiscuity and sexual sensation seeking which led to the experience of sexuality related behaviors through the use of internet or online resources (Bilal, 2021).

The second hypothesis was to predict cybersex addiction from psychopathy. The results of regression analysis showed that cybersex addiction significantly predicted cybersex addiction from psychopathy traits. This validates the previous studies establishing a direct link between psychopathy and cybersex addiction (Kircaburun \& Griffiths, 2018). This study is superior to those studies as it not only establishes an association between psychopathy and cybersex addiction but it also establishes a causal link between psychopathy and cybersex addiction. The psychopathy traits are associated with both Machiavellianism and narcissism which are the other traits in dark triad personality traits. The impulsive nature of psychopaths, their emotional mood dysregulation, and lack of empathy toward others are the traits that make them fit to develop cybersex addiction which then leads to loss of control to quit internet use, lack of self-esteem, callousness, and psychosexual impairments in interpersonal relationships (Van Geel, Goemans, Toprak, \& Vedder, 2017).

The male students in the present study were found to be significantly different from female students in both psychopathy and cybersex addiction. This finding is in line with previous studies (Brand et al., 2016) and our cultural norms (Ehsan et al., 2019). The males become easily addicted to cybersex as compared to females. This is so because males use cybersex activities as a way to regulate their emotions and mood and to derive pleasure while females do the cybersex activities to please their partners or in a partnered activity. It is often difficult for males to quit cybersex despite knowing about the negative consequences of cybersex addiction (Brand et al., 2016).

The students of age group 18-22 years were found to be high on both psychopathy and cybersex addiction as compared to students of age group 23-25 years. The previous studies validate this finding. The younger adults had the more chances and prevalence of cybersex addiction as compared with elder age groups. This shows that chances of engaging in psychopathy and cybersex addiction lower with the advancing age (Snagowski \& Brand, 2015; Weinstein et al., 2015).

\section{Conclusion}

The present study concluded that psychopathy trait and cybersex addiction were significantly and positively correlated. Further, the psychopathic personality traits in adolescents and young adults led to experience of cybersex addiction in undergraduate university students. The male university students were found to exhibit greater psychopathic traits and more cybersex addiction. It was suggested that there should be development 
appropriate sex education imparted by parents. Moreover, the parents should place a reasonable restriction on screen time of emerging adults so that they may not become victim to cybersex addiction.

The present research has implications for parents, teachers, and policy makers. The internet should be available to adolescents under parental supervision and guidance. The parents should discuss the internet supervision rules with their children. The age appropriate and culturally normative sex education need to be imparted to children by the parents. The government needs to develop a mechanism to monitor the internet use for adolescents and young adults.

The small sample size is the limitation of this study as findings from this study cannot be generalized to a broader university sample. The cultural sensitivity associated with the phenomena of cybersex addiction made it difficult for students to take part in the survey. Other demographic variables should have been included to make the research more informative.

\section{References}

American Psychiatric Association. (2013). Diagnostic and Statistical Manual of Mental Disorders (5th ed.). Washington DC: American Psychological Association.

Anderson, E. L., Steen, E., \& Stavropoulos, V. (2017). Internet use and problematic internet use: A systematic review of longitudinal research trends in adolescence and emergent adulthood. International Journal of adolescence and youth, 22(4), 430-454. doi:https://doi.org/10.1080/02673843.2016.1227716

Atiq-ur-Rehman, M., Ditta, A., Nawaz, M. A., \& Bashir, F. (2020). The Lucas Paradox and Institutional Quality: Evidence from Emerging Markets. Review of Economics and Development Studies, 6(2), 461-470. doi:https://doi.org/10.47067/reads.v6i2.223

Beutel, M. E., Brähler, E., Glaesmer, H., Kuss, D. J., Wölfling, K., \& Müller, K. W. (2011). Regular and problematic leisure-time Internet use in the community: results from a German population-based survey. Cyberpsychology, Behavior, and Social Networking, 14(5), 291-296. doi:https://doi.org/10.1089/cyber.2010.0199

Beutel, M. E., Giralt, S., Wölfling, K., Stöbel-Richter, Y., Subic-Wrana, C., Reiner, I., . . . Brähler, E. (2017). Prevalence and determinants of online-sex use in the German population. PLoS One, 12(6), e0176449. doi:https://doi.org/10.1371/journal.pone.0176449

Bilal, A. (2021). Sexting: Emotional promiscuity and sexual sensation seeking in Pakistani young adults. Liberal Arts and Social Sciences International Journal, 5(1), 75-88. doi:https://doi.org/10.47264/idea.lassij/5.1.6

Boies, S. C. (2002). University students' uses of and reactions to online sexual information and entertainment: links to online and offline sexual behavior. Canadian Journal of Human Sexuality, 11(2), 77-89.

Brand, M., Laier, C., Pawlikowski, M., Schächtle, U., Schöler, T., \& Altstötter-Gleich, C. (2011). Watching pornographic pictures on the Internet: Role of sexual arousal ratings and psychological-psychiatric symptoms for using Internet sex sites excessively. Cyberpsychology, Behavior, and Social Networking, 14(6), 371-377. doi:https://doi.org/10.1089/cyber.2010.0222

Brand, M., Young, K. S., \& Laier, C. (2014). Prefrontal control and Internet addiction: a theoretical model and review of neuropsychological and neuroimaging findings. Frontiers in human neuroscience, doi:https://doi.org/10.3389/fnhum.2014.00375

Brand, M., Young, K. S., Laier, C., Wölfling, K., \& Potenza, M. N. (2016). Integrating psychological and neurobiological considerations regarding the development and maintenance of specific Internet-use disorders: An Interaction of Person-AffectCognition-Execution (I-PACE) model. Neuroscience \& Biobehavioral Reviews, 71, 252266. doi:https://doi.org/10.1016/j.neubiorev.2016.08.033

Bridges, A. J., \& Morokoff, P. J. (2011). Sexual media use and relational satisfaction in heterosexual couples. Personal Relationships, 18(4), 562-585. doi:https://doi.org/10.1111/j.1475-6811.2010.01328.x 
Buckels, E. E., Trapnell, P. D., \& Paulhus, D. L. (2014). Trolls just want to have fun. Personality and individual Differences, 67, 97-102. doi:https://doi.org/10.1016/j.paid.2014.01.016

Cooper, A., Delmonico, D. L., \& Burg, R. (2000). Cybersex users, abusers, and compulsives: New findings and implications. Sexual Addiction \& Compulsivity: The Journal of Treatment and Prevention, 7(2), 5-29. doi:https://doi.org/10.1080/10720160008400205

Cooper, A., Griffin-Shelley, E., Delmonico, D. L., \& Mathy, R. M. (2001). Online sexual problems: Assessment and predictive variables. Sexual Addiction \&Compulsivity: The Journal of Treatment and Prevention, 8(4), 267-285. doi:https://doi.org/10.1080/107201601753459964

Dhuffar, M. K., \& Griffiths, M. D. (2015). A systematic review of online sex addiction and clinical treatments using CONSORT evaluation. Current Addiction Reports, 2(2), 163174. doi:https://doi.org/10.1007/s40429-015-0055-x

Edwards, D. (2009). Sign and symptoms of internet sexual addiction. Retrieved from https://www.payh.org/signs-and-symptoms-of-internet-sexual-addiction/

Egan, V., Chan, S., \& Shorter, G. W. (2014). The Dark Triad, happiness and subjective wellbeing. Personality and individual Differences, 67, 17-22. doi:https://doi.org/10.1016/j.paid.2014.01.004

Ehsan, S. M., Ahmed, S., Asim, A., Devi, M., \& Ahmad, F. (2019). Association between lack of sex education and watching of adult themed content amongst youngsters in Pakistan. Pakistan Journal of Medicine and Dentistry, 8(4), 87-93. doi:https://doi.org/10.36283/pjmd8-4/015

Giordano, A. L., \& Cashwell, C. S. (2017). Cybersex addiction among college students: A prevalence study. Sexual Addiction \& Compulsivity, 24(1-2), 47-57. doi:https://doi.org/10.1080/10720162.2017.1287612

Griffiths, M. (2001). Sex on the Internet: Observations and implications for Internet sex addiction. Journal of sex research, 38(4), 333-342. doi:https://doi.org/10.1080/00224490109552104

Hald, G. M., \& Mulya, T. W. (2013). Pornography consumption and non-marital sexual behaviour in a sample of young Indonesian university students. Culture, Health \& Sexuality, 15(8), 981-996. doi:https://doi.org/10.1080/13691058.2013.802013

Javed, M., Nawaz, M. A., \& Qurat-Ul-Ain, A. (2015). Assessing Postgraduate Students' Critical Thinking Ability. Journal on Educational Psychology, 9(2), 19-26.

Jonason, P. K., Zeigler-Hill, V., \& Okan, C. (2017). Good v. evil: Predicting sinning with dark personality traits and moral foundations. Personality and individual Differences, 104, 180-185. doi:https://doi.org/10.1016/j.paid.2016.08.002

Kafka, M. P. (2010). Hypersexual disorder: A proposed diagnosis for DSM-V. Archives of sexual behavior, 39(2), 377-400. doi:https://doi.org/10.1007/s10508-009-9574-7

Kayiş, A. R., Satici, S. A., Yilmaz, M. F., Şimşek, D., Ceyhan, E., \& Bakioğlu, F. (2016). Big five-personality trait and internet addiction: A meta-analytic review. Computers in Human Behavior, 63, 35-40. doi:https://doi.org/10.1016/j.chb.2016.05.012

Kircaburun, K., \& Griffiths, M. D. (2018). The dark side of internet: Preliminary evidence for the associations of dark personality traits with specific online activities and problematic internet use. Journal of behavioral addictions, 7(4), 993-1003. doi:https://doi.org/10.1556/2006.7.2018.109

Kuss, D. J., D Griffiths, M., Karila, L., \& Billieux, J. (2014). Internet addiction: A systematic review of epidemiological research for the last decade. Current pharmaceutical design, 20(25), 4026-4052.

Laier, C., Pawlikowski, M., Pekal, J., Schulte, F. P., \& Brand, M. (2013). Cybersex addiction: Experienced sexual arousal when watching pornography and not real-life sexual contacts makes the difference. Journal of behavioral addictions, 2(2), 100-107. doi:https://doi.org/10.1556/jba.2.2013.002

Laier, C., Pekal, J., \& Brand, M. (2014). Cybersex addiction in heterosexual female users of Internet pornography can be explained by gratification hypothesis. Cyberpsychology, Behavior, and Social Networking, 17(8), 505-511. doi:https://doi.org/10.1089/cyber.2013.0396

Lam, L. T., Peng, Z.-w., Mai, J.-c., \& Jing, J. (2009). Factors associated with Internet addiction among adolescents. Cyberpsychology \& behavior, 12(5), 551-555. doi:https://doi.org/10.1089/cpb.2009.0036 
Liau, A. K., Khoo, A., \& Ang, P. H. (2008). Parental awareness and monitoring of adolescent Internet use. Current psychology, 27(4), 217-233. doi:https://doi.org/10.1007/s12144008-9038-6

Lin, S. S., \& Tsai, C.-C. (2002). Sensation seeking and internet dependence of Taiwanese high school adolescents. Computers in Human Behavior, 18(4), 411-426. doi:https://doi.org/10.1016/S0747-5632(01)00056-5

Lu, W.-H., Lee, K.-H., Ko, C.-H., Hsiao, R. C., Hu, H.-F., \& Yen, C.-F. (2017). Relationship between borderline personality symptoms and Internet addiction: The mediating effects of mental health problems. Journal of behavioral addictions, 6(3), 434-441. doi:https://doi.org/10.1556/2006.6.2017.053

Marcus, D. K., Zeigler-Hill, V., Mercer, S. H., \& Norris, A. L. (2014). The psychology of spite and the measurement of spitefulness. Psychological assessment, 26(2), 563-574.

Nawaz, M. A., Afzal, N., \& Shehzadi, K. (2013). Problems of formally employed women: A case study of Bahawalnagar, Pakistan. Asian Journal of Empirical Research, 3(10), 12911299.

Nevin, A. D. (2015). Cyber-Psychopathy: Examining the relationship between dark Epersonality and online misconduct. (Master of Arts), The University of Western Ontario, London. Retrieved from https://ir.lib.uwo.ca/etd/2926

New Indian Express. (2019). Pakistan blocks 8,00,000 websites to curb pornography.

Nosko, A., Wood, E., \& Desmarais, S. (2007). Unsolicited online sexual material: what affects our attitudes and likelihood to search for more? The Canadian Journal of Human Sexuality, 16(1/2), 1-10.

Paul, B., \& Shim, J. W. (2008). Gender, sexual affect, and motivations for Internet pornography use. International Journal of Sexual Health, 20(3), 187-199. doi:https://doi.org/10.1080/19317610802240154

Reay, B., Attwood, N., \& Gooder, C. (2013). Inventing sex: The short history of sex addiction. Sexuality \& Culture, 17(1), 1-19. doi:https://doi.org/10.1007/s12119-012-9136-3

Short, M. B., Black, L., Smith, A. H., Wetterneck, C. T., \& Wells, D. E. (2012). A review of Internet pornography use research: Methodology and content from the past 10 years. Cyberpsychology, Behavior, and Social Networking, 15(1), 13-23. doi:https://doi.org/10.1089/cyber.2010.0477

Snagowski, J., \& Brand, M. (2015). Symptoms of cybersex addiction can be linked to both approaching and avoiding pornographic stimuli: Results from an analog sample of regular cybersex users. Frontiers in Psychology, 6, 1-14. doi:https://doi.org/10.3389/fpsyg.2015.00653

Van Geel, M., Goemans, A., Toprak, F., \& Vedder, P. (2017). Which personality traits are related to traditional bullying and cyberbullying? A study with the Big Five, Dark Triad and sadism. Personality and individual Differences, 106, 231-235. doi:https://doi.org/10.1016/j.paid.2016.10.063

Weinstein, A. M., Zolek, R., Babkin, A., Cohen, K., \& Lejoyeux, M. (2015). Factors predicting cybersex use and difficulties in forming intimate relationships among male and female users of cybersex. Frontiers in psychiatry, 6, 1-8. doi:https://doi.org/10.3389/fpsyt.2015.00054

Ybarra, M. L., \& Mitchell, K. J. (2005). Exposure to Internet pornography among children and adolescents: A national survey. Cyberpsychology \& behavior, 8(5), 473-486. doi:https://doi.org/10.1089/cpb.2005.8.473

Young, K. S. (1999). Internet addiction: Evaluation and treatment. British Medical Journal, 319(S4), 351-352. doi:https://doi.org/10.1136/sbmj.9910351

Young, K. S. (2008). Internet sex addiction: Risk factors, stages of development, and treatment. American Behavioral Scientist, 52(1), 21-37. doi:https://doi.org/10.1177/0002764208321339 